\title{
Impact of Storage Solution Formulation during Refrigerated Storage upon Chondrocyte Viability and Cartilage Matrix
}

\author{
Gregory J. Wright ${ }^{a}$ Kelvin G.M. Brockbank ${ }^{\text {b-d }}$ Eliza Rahn ${ }^{c}$ Dina O. Halwanic \\ Zhen Chen ${ }^{c}$ Hai Yao ${ }^{a, b}$ \\ ${ }^{a}$ Clemson-Medical University of South Carolina Joint Bioengineering Program, Department of Bioengineering, \\ Clemson University, ${ }^{b}$ Department of Regenerative Medicine and Cell Biology, Medical University of South Carolina, \\ Charleston, S.C., ${ }^{C}$ Cell and Tissue Systems, Inc., North Charleston, S.C., and ${ }^{d}$ Institute for Bioengineering and \\ Bioscience, Georgia Institute of Technology, Atlanta, Ga., USA
}

\section{Key Words}

Cartilage $\cdot$ Chondrocyte $\cdot$ Refrigerated storage $\cdot$ Viability ·

Metabolism $\cdot$ Matrix permeability

\begin{abstract}
Various preservation solutions have been evaluated for longer hypothermic cartilage storage for tissue transplantation; however, the results are mixed. This research was carried out to determine whether phosphate-buffered saline (PBS) or organ preservation solutions would preserve both the extracellular matrix and chondrocytes of articular cartilage better than culture medium during refrigerated storage in the time frame that cartilage is stored for clinical use. Porcine cartilage plugs were stored, without the underlying bone, in culture medium with and without fetal bovine serum (FBS), PBS, Belzer's and Unisol solutions for 1 month at $4^{\circ} \mathrm{C}$. Metabolic activity was tested using a resazurin reduction method, and matrix permeability was evaluated by measuring electrical conductivity. Storage in culture medium with $10 \%$ FBS was shown to provide good cartilage metabolic function for 7 days, decreasing to about $36 \%$ after 1 month of storage.
\end{abstract}

There was no significant difference between samples stored in culture medium with and without FBS after 1 month of storage $(p=0.5005)$. Refrigerated storage of cartilage in PBS and two different solutions (Belzer's and Unisol) designed for optimal refrigerated tissue and organ storage results in loss of chondrocyte function and retention of matrix permeability. In contrast, the opposite, namely significantly better retention of chondrocyte function and loss of matrix permeability, was observed with culture medium. Future research should be focused on combining retention of chondrocyte function and matrix permeability by storage solution formulation.

(c) 2014 S. Karger AG, Basel

\section{KARGER}

E-Mail karger@karger.com www.karger.com/cto
(C) 2014 S. Karger AG, Basel

1422-6405/14/1991-0051\$39.50/0 


\section{Introduction}

Donated donor-derived osteochondral tissue grafts are typically harvested within $24 \mathrm{~h}$ of donor death and banked at $4^{\circ} \mathrm{C}$ for up to 42 days for repair of clinical cartilage defects. Cartilage plugs are employed in mosaicplasty procedures for smaller defects less than $3 \mathrm{~cm}$ wide and less than $1 \mathrm{~cm}$ deep. Osteochondral allograft transplantation has been an effective treatment option with promising long-term clinical outcomes for larger focal posttraumatic defects in the knee for young, active individuals [Gross et al., 2008]. There were 15,797 allogeneic human articular cartilage procedures performed in the USA during 2006 [InteLab Corporation, 2009]. It is anticipated that many more procedures would be performed if better cartilage preservation methods were available.

The duration of hypothermic refrigerated storage of osteochondral grafts is rather unusual. Although the cells in heart valve leaflets persist for weeks during hypothermic refrigeration in culture medium [Brockbank et al., 1992; Taylor and Brockbank, 2003], most tissues are refrigerated for only hours before significant loss of cell viability and tissue function occurs. However, there are reports supporting chondrocyte survival for days or weeks of hypothermic storage in their natural extracellular matrix (ECM) in humans [Williams et al., 2003; Ball et al., 2004; Allen et al., 2005; Malinin et al., 2006] and several animal species [Black et al., 1979; Rodrigo et al., 1980; Wayne et al., 1990; Oates et al., 1995; Kim et al., 1996; Rohde et al., 2004; Williams et al., 2004; Malinin et al., 2006; Teng et al., 2008; Onuma et al., 2009]. Because such survival was considered unusual, compared with other tissue types, we previously initiated research to assess the impact of $4^{\circ} \mathrm{C}$ storage in Dulbecco's modified Eagle's medium (DMEM) culture medium on cartilage cell viability and establish whether or not cartilage plugs were an acceptable model compared with bisected femoral heads with both cartilage and bone tissue present [Brockbank et al., 2011b]. We also included ECM permeability evaluation during storage because prolonged storage of cartilage with viable cells might promote the release of enzymes that impact tissue material properties [Brockbank et al., 2011b]. We found that storage in DMEM culture medium with $10 \%$ fetal bovine serum (FBS) provides good cartilage viability for 7 days. In addition, there was a marked tendency for cartilage plugs to demonstrate higher viability values than the femoral heads. However, 1 month of storage of cartilage resulted in loss of both chondrocyte viability and ECM permeability [Brockbank et al., 2011b].
Various preservation solutions have been evaluated for longer hypothermic cartilage storage; however, the results are mixed. Onuma et al. [2009] compared DMEM, saline, EuroCollins solution and University of Wisconsin solution to determine which provided the best hypothermic preservation of rat osteochondral tissues. They concluded that University of Wisconsin solution, an intracellular-type solution, was the most suitable. In contrast, Teng et al. [2008] clearly demonstrated the positive impact of more complex culture media formulations upon chondrocyte survival such as DMEM, an extracellulartype solution. There are other indications in the literature that media supplementation or modification, such as FBS supplementation, might promote chondrocyte survival. However, FBS supplementation is also an issue for tissue bank products due to FBS batch variation and the associated health risks [Teng et al., 2008; Brockbank et al., 2011a]. At present, extensive research is still needed to determine what type of solution is best for chondrocyte preservation in cartilage and to define the optimal solution composition.

Therefore, the purpose of the research presented in this paper was to further investigate cartilage cell and biomaterial properties during storage in a common culture medium, hypothermic solutions designed for cell, tissue and organ storage and a commonly used salt solution. Moreover, the effect of FBS supplementation on cartilage cell viability was examined during storage in common culture medium. Improved storage solutions could result in increased utilization of banked allogeneic cartilage for reconstruction of articular cartilage defects and possibly storage and distribution of tissue-engineered cartilage.

\section{Materials and Methods}

\section{Specimen Preparation}

Articular cartilage, 2-3 mm thick, was obtained from the femoral weight-bearing condyles of animals after they were sacrificed for other experimental studies (bona fide excess tissues). Bona fide excess tissue is a term used to describe animal-derived materials obtained from animals after they have been sacrificed for other uses. Pig knees were procured from skeletally immature domestic Yorkshire cross farm pigs (30-60 kg, aged 4-8 months) at the conclusion of other Institutional Animal Care and Use Committee-approved research projects at the Medical University of South Carolina. These pigs were skeletally immature (maturity is achieved at weights $>200$ $\mathrm{kg}$ and 2 years of age). The knees were placed in zip lock bags with an iodine solution and transported on ice to our laboratory for aseptic dissection.
52

Cells Tissues Organs 2014;199:51-58 DOI: $10.1159 / 000363134$
Wright/Brockbank/Rahn/Halwani/ Chen/Yao 


\section{Study 1: Effect of FBS Supplementation}

In the first set of experiments, porcine femoral cartilage consisting of 6-mm cartilage plugs without the underlying bone were stored in high-glucose (25 mM) DMEM (Cat. No. 01-017 without sodium pyruvate, Mediatech, Manassas, Va., USA) with and without 10\% FBS (JR Scientific, Woodland, Calif., USA) for 1 week or 1 month at $4{ }^{\circ} \mathrm{C}$. Cartilage plugs not stored for any period of time were used as fresh untreated control. Cell viability was examined at the end of each storage period. Cartilage plugs from 2 donor pigs were harvested for this study. There were 6 cartilage plugs for each tested group.

\section{Study 2: Effect of Storage Solution}

In the second set of experiments, 6-mm cartilage plugs were stored in DMEM with 10\% FBS, Belzer's solution (SPS-1, Organ Recovery Systems, Inc., Itasca, Ill., USA), Unisol solution (Cell and Tissue Systems, Charleston, S.C., USA) or phosphate-buffered saline (PBS) for 1 month at $4^{\circ} \mathrm{C}$. Formulations of the SPS- 1 and Unisol solutions are shown in table 1 . The media were changed weekly. Cartilage plugs from 4 donor pigs were used in this study and were mixed and randomly assigned to each tested group. The cell viability of cartilage plugs was examined during a 4-day recovery period after 1 month of hypothermic storage. The cartilage plugs were recovered in DMEM with $10 \% \mathrm{FBS}$ at $37^{\circ} \mathrm{C}$. There were 20 cartilage plugs for each tested group in each experiment. The tissue matrix permeability before and after 1 month of hypothermic storage was examined using the electrical conductivity method. There were 20 cartilage plugs for each tested group.

\section{Viability Assessment}

Chondrocyte metabolic activity was assessed using the resazurin reduction method. The resazurin reduction assay incorporates a water-soluble fluorometric viability oxidation-reduction indicator which detects metabolic activity by both fluorescing and changing color in response to chemical reduction of the growth medium. Metabolically active cells reduce resazurin to fluorescing resorufin [O'Brien et al., 2000]. Fresh control and hypothermically stored tissue samples were placed in $37^{\circ} \mathrm{C}$ culture conditions for $1 \mathrm{~h}$ to permit adjustment to tissue culture conditions in DMEM plus $10 \%$ FBS. The tissues were then incubated for $3 \mathrm{~h}$ with resazurin working solution, after which aliquots of medium were placed in microtiter plate wells and read on a microtiter plate spectrofluorometer at a wavelength of $590 \mathrm{~nm}$. The data are expressed as means \pm standard deviation in relative fluorescence units after subtraction of baseline florescence from incubation controls containing the same amount of culture medium and resazurin reagent without tissue.

\section{Biomaterial Testing}

Cartilage plugs were also evaluated for permeability by measuring their electrical conductivity to determine if cartilage matrix characteristics were being altered during storage. Specimens were prepared by cutting a 5 - $\mathrm{mm}$ cylindrical plug using a corneal trephine from the stored 8-mm-diameter cartilage discs. The samples were tested after 0 and 1 month of storage; the cartilage surfaces were trimmed manually using a sharp blade. The average height after trimming was $1.53 \pm 0.27 \mathrm{~mm}$. Subsequently, conductivity was tested, first in isotonic PBS and then after swelling in hypotonic saline $(0.2 \times$ PBS). The electrical conductivity was measured based on the principle of a 4 -wire resistance test using a Keithley Source-
Table 1. Formulations of intracellular-type solutions used for cartilage storage

\begin{tabular}{lll}
\hline Components & Unisol I & SPS-1 \\
\hline Ionic, mmol/l & & \\
$\mathrm{Na}^{+}$ & 62.5 & 30 \\
$\mathrm{~K}^{+}$ & 70.0 & 125 \\
$\mathrm{Ca}^{++}$ & 0.05 & - \\
$\mathrm{Mg}^{++}$ & 15.0 & 5.0 \\
$\mathrm{Cl}^{-}$ & 30.1 & - \\
$\mathrm{SO}_{4}^{-}$ & - & 5.0 \\
$\mathrm{pH} \mathrm{buffers,} \mathrm{mmol/l}^{-}$ & & \\
$\mathrm{H}_{2} \mathrm{PO}_{4}^{-}$ & 2.5 & 25 \\
$\mathrm{HCO}_{3}^{-}$ & 5.0 & - \\
$\quad \mathrm{HEPES}^{-}$ & 35.0 & - \\
Impermeants, mmol/l & & \\
Lactobionate & & \\
Sucrose & 30.0 & 100 \\
$\quad$ Mannitol & 25.0 & - \\
$\quad$ Glucose & 25.0 & - \\
$\quad$ Gluconate & 5.0 & - \\
$\quad$ Raffinose & 70.0 & - \\
Colloids & - & 30 \\
$\quad$ Hydroxyethyl starch & - & \\
Pharmacologics, mmol/l & & $50 \mathrm{~g} / \mathrm{l}$ \\
$\quad$ Adenosine & 2.0 & 5.0 \\
$\quad$ Glutathione & 3.0 & 3.0 \\
$\quad$ Allopurinol & - & $0.136 \mathrm{~g} / \mathrm{l}$ \\
Osmolality, mosm/kg & 350 & 320 \\
pH & 7.6 & 7.4 \\
\hline
\end{tabular}

meter (Model 2400, Keithley Instruments, Inc., Cleveland, Ohio, USA) and a custom-designed conductivity chamber as reported previously [Gu et al., 2002; Brockbank et al., 2011b]. Briefly, the conductivity apparatus consists of two stainless steel current electrodes coaxial to two Teflon-coated $\mathrm{Ag} / \mathrm{AgCl}$ voltage electrodes placed on the top and bottom of a cylindrical nonconductive Plexiglass chamber (5-mm diameter). The specimen was placed inside the chamber for measurement. The resistance $(R)$ values across the specimens were measured at a low, constant direct current density of $0.015 \mathrm{~mA} / \mathrm{cm}^{2}$. The height of the specimen was measured with an electrical current-sensing micrometer. The electrical conductivity $(\chi)$ values of the specimens were calculated by

$$
\chi=\frac{h}{R \cdot A},
$$

where $h$ and $A$ are the height and cross-sectional area of the specimens, respectively. The precision for the resistance measurements was $0.5 \Omega$, while the height measured with an accuracy of $\pm 1.0 \mu \mathrm{m}$. All electrical conductivity measurements were performed at room temperature $\left(22^{\circ} \mathrm{C}\right)$. Electrical conductivity is a material property of biological tissues. Its value is related to the diffusivity of small ions in the tissue, which depends upon tissue composition and structure [Maroudas, 1968; Frank et al., 1990]. Using an electrical conductivity method, the effect of matrix composition on solute 


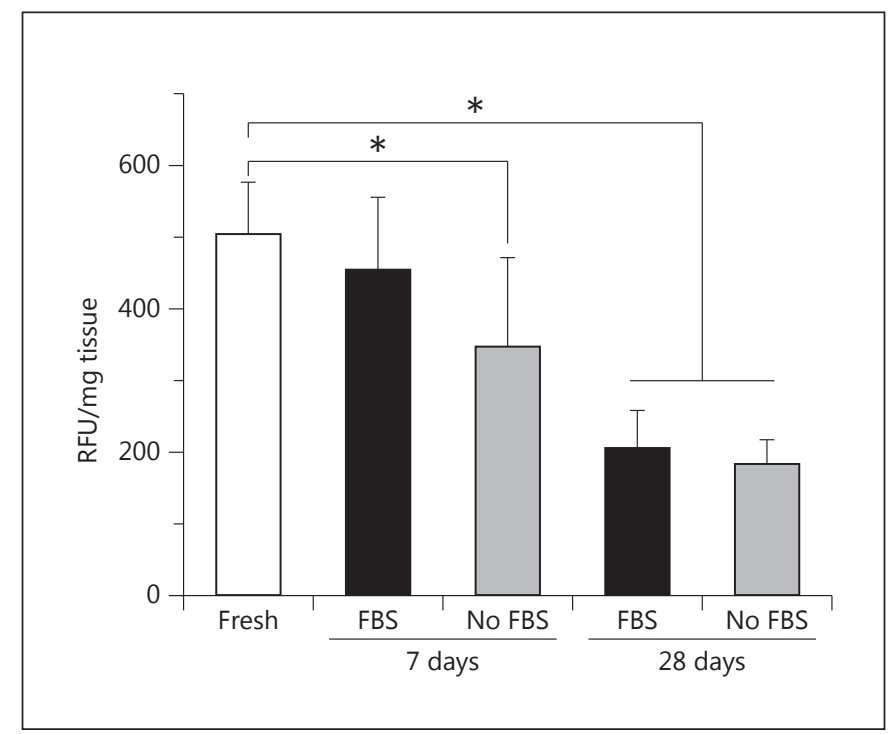

Fig. 1. Chondrocyte viability during cartilage plug hypothermic storage in culture medium with and without FBS assessed by the resazurin reduction metabolic assay $(n=6)$. The data shown are means \pm standard deviations. ${ }^{*} \mathrm{p}<0.05$ compared to fresh controls. RFU $=$ Relative fluorescence units.

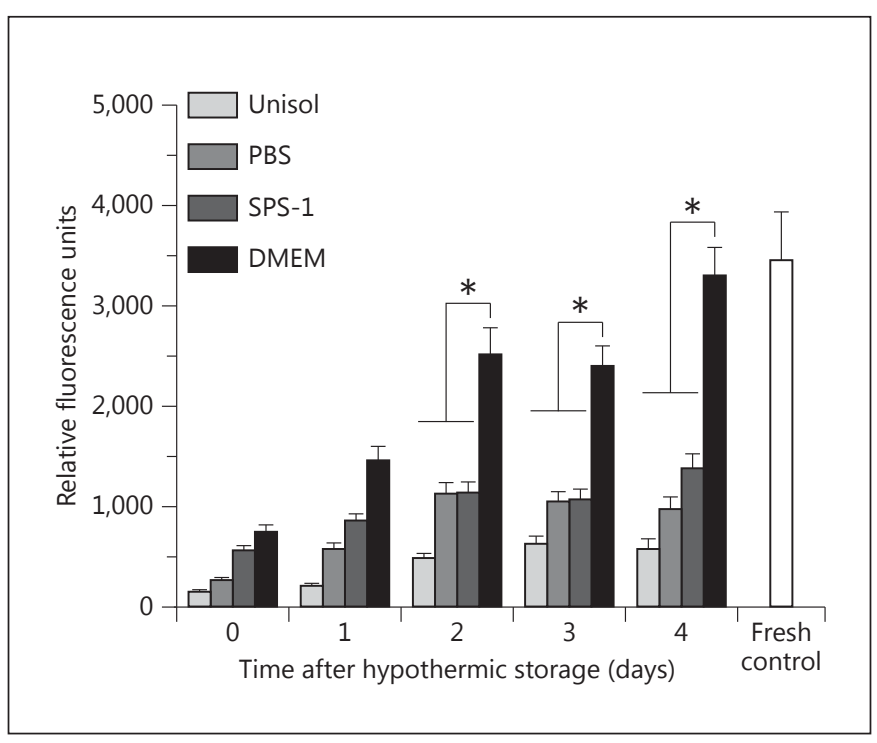

Fig. 2. Comparison of chondrocyte metabolic functions after storage in intracellular-type and extracellular-type solutions $(n=20)$. Function was assessed by the resazurin reduction metabolic assay. The data are expressed as means \pm standard deviation. ${ }^{*} \mathrm{p}<0.05$ compared to DMEM containing 10\% FBS. Significant differences were observed between DMEM containing 10\% FBS and the other alternative solutions starting at day 2. DMEM containing 10\% FBS achieved progressive increases in cell viability, reaching control levels at day 4 . Fresh control values are shown at the right of the figure. permeability has previously been studied in hydrogels and cartilaginous tissues [ $\mathrm{Gu}$ et al., 2004; Jackson and $\mathrm{Gu}, 2009$ ]. In this study, we adopted this method to study the impact of $4^{\circ} \mathrm{C}$ storage on cartilage ECM solute permeability. It could be considered that the measured electrical conductivity mainly represents the tissue property since chondrocytes normally occupy $1-10 \%$ of the volume of articular cartilage [Stockwell, 1978]. Moreover, the transport of small solutes (e.g. ions, oxygen and glucose) within avascular cartilage tissues mainly depends on diffusion [Yao and $\mathrm{Gu}, 2007$ ]. Therefore, electrical conductivity was selected in addition to cell viability in order to evaluate tissue ECM changes that may affect nutrient transport ability as well as mechanical function in vivo.

\section{Statistical Analysis}

The measurements are presented as means \pm standard deviation. One-way analysis of variance with Tukey's post hoc analysis $(\mathrm{p}<0.05)$ was conducted to determine differences in mean values of cell fluorescence units and electrical conductivity. In study 1 , the effect of FBS supplementation on cell viability $(n=6)$ was examined. In study 2 , the effect of storage solution on cell viability ( $\mathrm{n}=$ $20)$, as well as on electrical conductivity $(n=20)$, was examined. SPSS 16.0 software (SPSS Inc., Chicago, Ill., USA) was used for all statistical analyses, and significant differences were reported at $\mathrm{p}$ values $<0.05$.

\section{Results}

In study 1, the effect of FBS supplementation on chondrocyte metabolic activity was assessed using the resazurin reduction method, and results are shown in figure 1. After 7 days of storage, the chondrocyte metabolic activity of cartilage plugs stored in DMEM with $10 \%$ FBS was not significantly different from the value of fresh controls $(\mathrm{p}=0.3879)$, while the metabolic activity of cartilage plugs stored in DMEM without $10 \%$ FBS was significantly lower than the value of fresh controls $(p=0.0339)$. Extended storage reduced the cartilage metabolic activity. The metabolic activity of cartilage samples dropped to about $36 \%$ of the value of the fresh controls after 1 month of storage. There was no significant difference between samples stored with and without FBS after 1 month of storage $(\mathrm{p}=0.5005)$.

In study 2 , cartilage samples were stored at $4{ }^{\circ} \mathrm{C}$ for 1 month in 1 of 3 solutions or culture medium with $10 \%$ FBS followed by evaluation of cell metabolic activity and matrix permeability. All solutions resulted in decreased chondrocyte viability after 1 month of storage $(<21 \%$ of fresh controls); however, during 4-day follow-up evaluations under cell culture conditions, culture medium supplemented with $10 \%$ FBS resulted in significantly higher viability compared with the 3 alternative solutions starting on day 2 ( $\mathrm{p}<0.0081)$, reaching fresh control viability values on day 4 (fig. 2). Simultaneously, samples were 


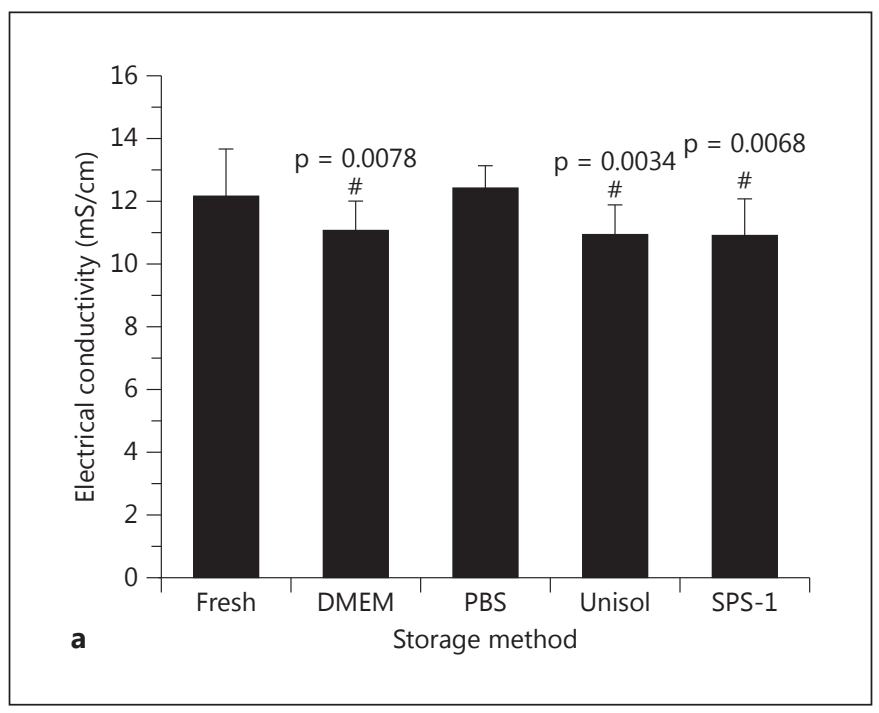

Fig. 3. Impact of hypothermic storage of cartilage in intracellulartype and extracellular-type solutions on electrical conductivity in isotonic saline (a) and hypotonic saline $(\mathbf{b} ; \mathrm{n}=20)$. The data are expressed as means \pm standard deviation. ${ }^{\#} \mathrm{p}<0.05$ compared to fresh control. ${ }^{*} \mathrm{p}<0.05$ compared to the other groups. In hypo-

prepared for matrix permeability assessment using the electrical conductivity method. When the plugs were tested in isotonic saline, significant differences in electrical conductivity were observed between the control and plugs stored in culture medium with FBS $(\mathrm{p}=0.0078)$, Unisol ( $\mathrm{p}=0.0034)$ and SPS- $1(\mathrm{p}=0.0068$; fig. 3a). The differences in isotonic solution were small; however, they were statistically significant and were magnified when the samples were subsequently swollen in hypotonic solution for testing (fig. 3b). The electrical conductivity of samples stored in culture medium was lower than the values of the samples stored in the other storage solutions $(\mathrm{p}<0.0001)$ and only about $60 \%$ of the value of the fresh control (fig. 3b).

\section{Discussion}

Chondrocyte viability at the time of implantation is an important factor in ensuring long-term allograft survival in vivo [Beaver et al., 1992; Bakay et al., 1998]. Commercially available fresh osteoarticular allografts are stored for at least 17 days to allow serologic and microbiologic testing prior to implantation because of concerns about potential infection [Williams et al., 2003; LaPrade et al., 2009]. We found, in agreement with our prior study

Effect of Storage Solution on Cartilage

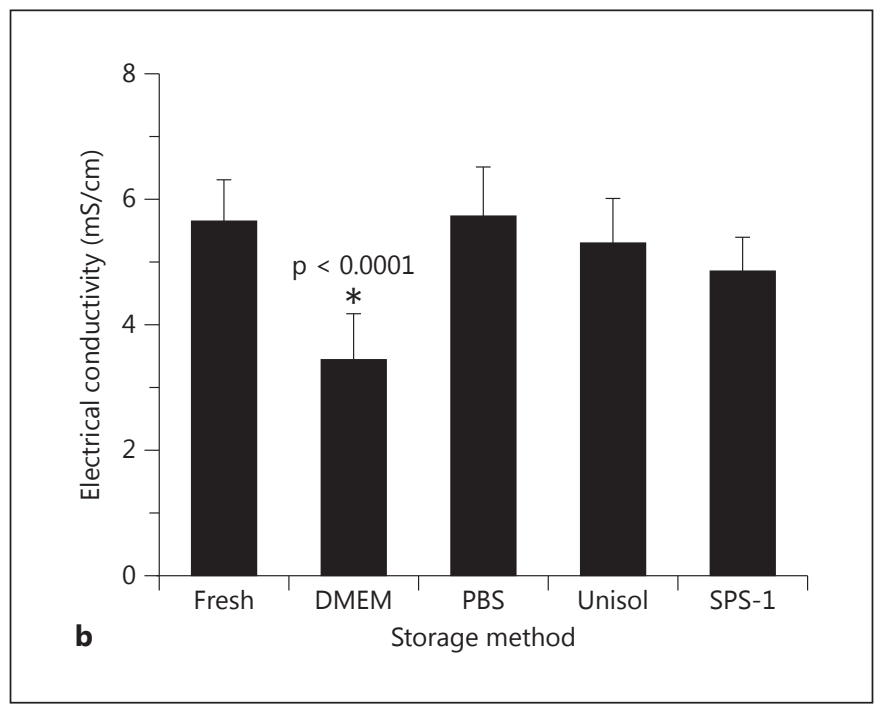

tonic saline, the electrical conductivity of samples stored in DMEM containing $10 \%$ FBS was lower than the values of the samples stored in the other storage solutions $(p<0.0001)$ and only about $60 \%$ of that of the fresh control.

[Brockbank et al., 2011b], that storage in DMEM culture medium with $10 \%$ FBS provides good cartilage viability for 7 days. In that study [Brockbank et al., 2011b], we compared the assay employed in the present study with Trypan blue. The metabolic assay provided higher cell viability values at 7 days than Trypan blue; by 28 days the results using the two assays were similar, with less than $30 \%$ cell viability. Our interpretation of the results was that many of the chondrocytes may have been damaged at 7 days, resulting in loss during the cell isolation procedures employing collagenase, required prior to the determination of cell viability using Trypan blue. This may also explain concerns previously expressed regarding the use of fluorescent assays for cartilage storage studies [Lightfoot et al., 2007]. It is possible that the metabolic assay at this time point is an accurate measure of potential viability if the tissues were implanted rather than subjected to collagenase digestion. The Trypan blue-excluding cells from fresh and both 7- and 28-day-stored tissues were also able to proliferate. Qualitatively similar-appearing cultures were obtained after 1 week under physiological conditions provided that consistent numbers of Trypan blue-excluding cells were plated.

The presence of FBS improved cell survival after the first week of storage, but there was no difference in cartilage viability between samples stored with and without 
FBS after 1 month of storage (fig. 1). This last observation leads us to believe that with further culture medium supplementation, it may be possible to remove FBS from osteochondral storage solutions, reducing concerns about FBS batch variation and the associated health risks [Teng et al., 2008; Brockbank et al., 2011a].

Comparison of tissue metabolic activity after hypothermic storage in solutions employed for organ and tissue storage (SPS-1 and Unisol), complex DMEM culture media supplemented with FBS and simple PBS yielded unanticipated results (fig. 2). Belzer's solution (SPS-1) and Unisol are both examples of 'intracellular-type' preservation solutions which are typically hypertonic and formulated to restrict the passive exchange of water and ions during hypothermia-induced inhibition of cell membrane pumps [reviewed in Brockbank and Taylor, 2007]. An intracellular-type solution usually includes a nonpermeating anion such as lactobionate or gluconate to partially replace chloride ions in the extracellular space. This provides osmotic support to balance the intracellular oncotic pressure generated by cytosolic macromolecules and their associated counter-ions locked inside the cell. In contrast, saline and culture media are 'extracellulartype' solutions [Brockbank and Taylor, 2007]. They are isotonic with a plasma-like complement of ions that mimics the normal extracellular environment of cells. Culture media contain a more complete complement of ions, amino acids and other metabolites that mimic the extracellular composition of plasma while providing nutritional support. PBS is a simple formulation consisting of salts and a buffer without nutritional components. Prolonged hypothermic storage of cells and tissue in extracellular media usually results in cell swelling, due to cold inactivation of membrane pumps, and cell death [Brockbank and Taylor, 2007].

Most published studies on cartilage hypothermic storage have employed extracellular-type solutions. However, Onuma et al. [2009] compared DMEM, saline, EuroCollins and Belzer's solutions to determine which provided the best hypothermic preservation of rat osteochondral tissues. They concluded on the basis of two assays and histology that Belzer's solution (SPS-1) was the most suitable. In contrast, Teng et al. [2008] clearly demonstrated the positive impact of more complex culture media formulation upon chondrocyte survival, such as DMEM, especially when supplemented with insulin growth factor-1 or an apoptosis inhibitor (Z-VAD-fmk). Our results confirm that complex extracellular-type culture media are best for maintenance of chondrocyte functions, which we have previously shown to correlate with cell survival using Trypan blue [Brockbank et al., 2011b]. The three alternative solutions, compared to DMEM, resulted in less metabolic activity after 1 month, which reached statistical significance during follow-up recovery incubation under physiologic tissue culture conditions. The resazurin metabolic assay has an advantage over other more commonly employed assays of being noncytotoxic, so the same piece of tissue can be assayed several times, as we have done in this study (fig. 2). Single time point use of the resazurin assay may be hard to interpret due to fluxes in metabolic activity during recovery from experimental insults or delayed cell death. This could lead to high readouts compared to assays such as Trypan blue [Brockbank et al., 2011b]. Alternatively, as already discussed, the differences observed could be due to reversibly damaged cells that are then further damaged by the isolation procedure required prior to Trypan blue evaluation. A deficiency of the resazurin assay in contrast with intracellular viability indicators using florescent microscopy methods is that the assay does not discriminate between cartilage zones, so the results obtained with this assay are the mean of the entire sample. An alternative way to express our data is to measure DNA content, after the tissue digestion, estimate the number of cells present using the conversion 7.7 pg of DNA per cell [Kim et al., 1988] and then extrapolate the relative metabolic activity per cell. We have expressed the resazurin results in relative florescence units per milligram of dry weight of tissue. Future experiments are planned to determine whether the recovery observed in the culture medium group is due to cells recovering from reversible injuries or proliferation.

However, when cartilage permeability was assessed, the 3 alternative solutions all resulted in better retention of permeability, in marked contrast with the significant permeability decrease observed for cartilage stored in complex extracellular-type media (fig. 3b) [Brockbank et al., 2011b]. The values of the electrical conductivity in this study are comparable to those in the literature for articular cartilage [Hasegawa et al., 1983]. The electrical conductivity of porcine articular cartilage measured in this study $(11.51 \pm 0.73 \mathrm{mS} / \mathrm{cm})$ is higher than the values for human articular cartilage $(6-10 \mathrm{mS} / \mathrm{cm})$ [Hasegawa et al., 1983]. The higher electrical conductivity in young porcine articular cartilage is likely due to higher tissue porosity (water content) compared with that in human articular cartilage. The value of electrical conductivity is related to the diffusivity of small ions in the tissue, which depends upon tissue composition and structure [Maroudas, 1968; Frank et al., 1990]. Using an electrical conductivity meth-
56

Cells Tissues Organs 2014;199:51-58 DOI: $10.1159 / 000363134$
Wright/Brockbank/Rahn/Halwani/ Chen/Yao 
od, the effect of matrix composition on solute permeability has previously been studied in hydrogels and cartilaginous tissues [Gu et al., 2004; Jackson and Gu, 2009; Kuo et al., 2011]. These studies show that the electrical conductivity is positively correlated with tissue porosity (i.e. water volume fraction) in cartilaginous tissues (e.g. articular cartilage, intervertebral discs and temporomandibular joint discs). This may be attributed to an increase in ion diffusivities with porosity. The hydration/porosity of articular cartilage is maintained by the glycosaminoglycan (GAG) content through the osmotic swelling mechanism. The fixed negative charge on the GAGs attracts counter-ions and gives rise to Donnan osmotic pressure, which favors tissue hydration [Maroudas, 1968; Frank et al., 1990]. This fixed charge-induced Donnan osmotic swelling is more significant in hypotonic conditions. A decrease in fixed charge density due to a decrease in GAG content will reduce tissue porosity, resulting in a decrease in electrical conductivity. It has been shown that trypsin-treated porcine anulus fibrosus has a lower porosity and electrical conductivity compared to control tissue [Gu et al., 2002]. In this study, for cartilage stored in complex extracellular-type media, the decrease in the electrical conductivity may be due to the decrease in the porosity caused by the decrease in the GAG content. Maintenance of living metabolizing cells in this cartilage may lead to production of functional enzymes that subsequently degrade the ECM, decreasing its GAG content. In the future, the change in tissue porosity and GAG contents in stored cartilage needs to be further determined.

Cartilage tissue comprises a solid and fluid phase and it may be treated as a biphasic material [Mow et al., 1980]. Cartilage executes its biomechanical role in the body to absorb and distribute joint stresses based on the mechanism of fluid pressurization [Soltz and Ateshian, 2000]. Therefore, the permeability characteristic is an important mechanical property of cartilage that is often overlooked in contrast to more commonly studied tensile or compressive parameters. Studies of such biomechanical parameters in the literature have consistently failed to demonstrate any changes in cold-stored cartilage. We previously observed ECM damage in frozen articular cartilage using laser scanning microscopy [Brockbank et al., 2008] and permeability deterioration during hypothermic storage of cartilage [Brockbank et al., 2011b]. Permeability changes were observed during both isotonic and hypotonic testing, and the differences were greater in hypotonic saline than in isotonic saline. Hypotonic solution made the tests more sensitive due to increased tissue swelling which magnified changes in the highly charged ECM [Gu et al., 2002].
Our working hypothesis to explain the new permeability data is that maintenance of living metabolizing cells in the cartilage leads to production of functional enzymes that subsequently degrade the ECM, decreasing its permeability. The rationale for this is that none of the 3 solutions that resulted in retention of permeability supported cell functions to the same degree as culture medium. Experimental enzyme treatment with trypsin has been previously shown to alter the permeability of intervertebral discs [Gu et al., 2002; Gu and Yao, 2003]. Further experiments designed to determine whether the release of endogenous enzymes, metalloproteinases, results in cartilage permeability changes are in progress. Biochemical assays are also being included to directly measure changes in biochemical composition (e.g. water, collagen and GAG content). Laser scanning microscopy [Brockbank et al., 2008] and Raman spectroscopy [Votteler et al., 2012] may also provide useful information on changes in collagen structure during hypothermic storage.

\section{Acknowledgements}

This project was supported by NIH grants DE021134, DE018741 and AR055775 to H.Y., NIH grant AR064033 to K.G.M.B., NIH F31 predoctoral fellowship DE023486 to G.J.W. and Industrial Student Internship support from the Georgia Institute of Technology to E.R.

\section{Disclosure Statement}

K.G.M.B. is an owner and employee of Cell and Tissue Systems. Z.C. and D.O.H. are employees of Cell and Tissue Systems. None of the other authors of this paper have any potential conflicts of interest that might be construed as affecting the conduct or reporting of the work presented.

\footnotetext{
References Allen, R.T., C.M. Robertson, A.T. Pennock, W.D. Bugbee, F.L. Harwood, V.W. Wong, A.C. Chen, R.L. Sah, D. Amiel (2005) Analysis of stored osteochondral allografts at the time of surgical implantation. Am J Sports Med 33: 1479-1484

Bakay, A., L. Csonge, G. Papp, L. Fekete (1998) Osteochondral resurfacing of the knee joint with allograft. Clinical analysis of 33 cases. Int Orthop 22: 277-281.

Ball, S.T., D. Amiel, S.K. Williams, W. Tontz, A.C. Chen, R.L. Sah, W.D. Bugbee (2004) The effects of storage on fresh human osteochondral allografts. Clin Orthop Relat Res (418): 246252 .
} 
Beaver, R.J., M. Mahomed, D. Backstein, A. Davis, D.J. Zukor, A.E. Gross (1992) Fresh osteochondral allografts for post-traumatic defects in the knee. A survivorship analysis. J Bone Joint Surg Br 74: 105-110.

Black, J., C.A. Shadle, J.R. Parsons, C.T. Brighton (1979) Articular cartilage preservation and storage. II. Mechanical indentation testing of viable, stored articular cartilage. Arthritis Rheum 22: 1102-1108.

Brockbank, K.G., J.F. Carpenter, P.E. Dawson (1992) Effects of storage temperature on viable bioprosthetic heart valves. Cryobiology 29: 537-542.

Brockbank, K.G., A.E. Heacox, K. Schenke-Layland (2011a) Guidance for removal of fetal bovine serum from cryopreserved heart valve processing. Cells Tissues Organs 193: 264 273.

Brockbank, K.G., W.R. MacLellan, J. Xie, S.F. Hamm-Alvarez, Z.Z. Chen, K. Schenke-Layland (2008) Quantitative second harmonic generation imaging of cartilage damage. Cell Tissue Bank 9: 299-307.

Brockbank, K.G., E. Rahn, G.J. Wright, Z. Chen, H. Yao (2011b) Impact of hypothermia upon chondrocyte viability and cartilage matrix permeability after 1 month of refrigerated storage. Transfus Med Hemother 38: $387-$ 392.

Brockbank, K.G.M., M.J. Taylor (2007) Tissue preservation; in Baust, J.G., J.M. Baust (eds): Advances in Biopreservation. Boca Raton, CRC Press/Taylor \& Francis, pp 157-196.

Frank, E.H., A.J. Grodzinsky, S.L. Phillips, P.E. Grimshaw (1990) Physiochemical and bioelectrical determinants of cartilage material properties; in Mow, V.C., D.O. Wood, S.L. Woo (eds): Biomechanics of Diarthrodial Joints. New York, Springer, pp 261-282.

Gross, A.E., W. Kim, F. Las Heras, D. Backstein, O. Safir, K.P. Pritzker (2008) Fresh osteochondral allografts for posttraumatic knee defects: long-term followup. Clin Orthop Relat Res 466: 1863-1870.

Gu, W.Y., M.A. Justiz, H. Yao (2002) Electrica conductivity of lumbar anulus fibrosis: effects of porosity and fixed charge density. Spine (Phila Pa 1976) 27: 2390-2395.

Gu, W.Y., H. Yao (2003) Effects of hydration and fixed charge density on fluid transport in charged hydrated soft tissues. Ann Biomed Eng 31: 1162-1170.
Gu, W.Y., H. Yao, A.L. Vega, D. Flagler (2004) Diffusivity of ions in agarose gels and intervertebral disc: effect of porosity. Ann Biomed Eng 32: 1710-1717.

Hasegawa, I., S. Kuriki, S. Matsuno, G. Matsumoto (1983) Dependence of electrical conductivity on fixed charge density in articular cartilage. Clin Orthop Relat Res 177: 283-288.

InteLab Corporation (2009) Worldwide markets and emerging technologies for tissue engineering and regenerative medicine. Marketing and Technology Reports.

Jackson, A., W. Gu (2009) Transport properties of cartilaginous tissues. Curr Rheumatol Rev 5: 40-50.

Kim, Y.J., R.L. Sah, J.Y. Doong, A.J. Grodzinsky (1988) Fluorometric assay of DNA in cartilage explants using Hoechst 33258. Anal Biochem 174: 168-176.

Kim, W., J.P. Vacanti, D. Mooney, J. Upton, C. Ibarra, C.A. Vacanti (1996) Functional viability of chondrocytes stored at 4 degrees C. Tissue Eng 2: 75-81.

Kuo, J., G.J. Wright, D.E. Bach, E.H. Slate, H. Yao (2011) Effect of mechanical loading on electrical conductivity in porcine TMJ discs. J Dent Res 90: 1216-1220.

LaPrade, R.F., J. Botker, M. Herzog, J. Agel (2009) Refrigerated osteoarticular allografts to treat articular cartilage defects of the femoral condyles. A prospective outcomes study. J Bone Joint Surg Am 91: 805-811.

Lightfoot, A., J. Martin, A. Amendola (2007) Fluorescent viability stains overestimate chondrocyte viability in osteoarticular allografts. Am J Sports Med 35: 1817-1823.

Malinin, T., H.T. Temple, B.E. Buck (2006) Transplantation of osteochondral allografts after cold storage. J Bone Joint Surg Am 88: 762-770.

Maroudas, A. (1968) Physicochemical properties of cartilage in the light of ion exchange theory. Biophys J 8: 575-595.

Mow, V.C., S.C. Kuei, W.M. Lai, C.G. Armstrong (1980) Biphasic creep and stress relaxation of articular cartilage in compression? Theory and experiments. J Biomech Eng 102: 73-84.

O’Brien, J., I. Wilson, T. Orton, F. Pognan (2000) Investigation of the Alamar Blue (resazurin) fluorescent dye for the assessment of mammalian cell cytotoxicity. Eur J Biochem 267: 5421-5426.

Oates, K.M., A.C. Chen, E.P. Young, M.K. Kwan, D. Amiel, F.R. Convery (1995) Effect of tissue culture storage on the in vivo survival of canine osteochondral allografts. J Orthop Res 13: $562-569$.
Onuma, K., K. Urabe, K. Naruse, H.J. Park, K. Uchida, M. Itoman (2009) Cold preservation of rat osteochondral tissues in two types of solid organ preservation solution, culture medium and saline. Cell Tissue Bank 10: 1-9.

Rodrigo, J., E. Thompson, C. Travis (1980) 4 degree $\mathrm{C}$ preservation of avascular osteocartilaginous shell allografts in rats. Trans Orthop Res Soc 5: 72 .

Rohde, R.S., R.K. Studer, C.R. Chu (2004) Minipig fresh osteochondral allografts deteriorate after 1 week of cold storage. Clin Orthop Relat Res (427): 226-233.

Soltz, M.A., G.A. Ateshian (2000) Interstitial fluid pressurization during confined compression cyclical loading of articular cartilage. Ann Biomed Eng 28: 150-159.

Stockwell, R.A. (1978) Chondrocytes. J Clin Pathol Suppl (R Coll Pathol) 12: 7-13.

Taylor, M.J., K.G.M. Brockbank (2003) Frontiers in biopreservation technology: Challenges for the storage of living tissues and engineered constructs; in Klatz, R.M., R. Goldman (eds): Anti-aging Medical Therapeutics. Marina Del Rey, Health Quest Publications, pp 515-526.

Teng, M.S., A.S. Yuen, H.T. Kim (2008) Enhancing osteochondral allograft viability: effects of storage media composition. Clin Orthop Relat Res 466: 1804-1809.

Votteler, M., D.A. Carvajal Berrio, M. Pudlas, H. Walles, U.A. Stock, K. Schenke-Layland (2012) Raman spectroscopy for the non-contact and non-destructive monitoring of collagen damage within tissues. J Biophotonics 5: 47-56.

Wayne, J.S., D. Amiel, M.K. Kwan, S.L. Woo, A. Fierer, M.H. Meyers (1990) Long-term storage effects on canine osteochondral allografts. Acta Orthop Scand 61: 539-545.

Williams, R.J. 3rd, J.C. Dreese, C.T. Chen (2004) Chondrocyte survival and material properties of hypothermically stored cartilage: an evaluation of tissue used for osteochondral allograft transplantation. Am J Sports Med 32: 132-139.

Williams, S.K., D. Amiel, S.T. Ball, R.T. Allen, V.W. Wong, A.C. Chen, R.L. Sah, W.D. Bugbee (2003) Prolonged storage effects on the articular cartilage of fresh human osteochondral allografts. J Bone Joint Surg Am 85- $A$ : 2111-2120.

Yao, H., W.Y. Gu (2007) Convection and diffusion in charged hydrated soft tissues: a mixture theory approach. Biomech Model Mechanobiol 6: 63-72. 